\title{
Visual attention in reading: Eye movements reflect cognitive processes
}

\author{
KEITH RAYNER \\ University of Rochester, Rochester, New York 14627
}

\begin{abstract}
Two hypotheses regarding the nature of fixation durations in reading were discussed. One position suggests that semantic processing lags behind the perceptual input of information. The other position suggests that semantic processing is more rapid and immediate. Eye movement data of skilled readers reading passages of text were analyzed. It was found that the main verb of the sentence received more visual attention than other key grammatical elements within a sentence. On the basis of the overall result pattern, it was argued that eye movements are affected by cognitive processes occurring at the time of the fixations.
\end{abstract}

During reading the eyes make saccadic eye movements separated by fixational pauses. The mean extent of the saccade is about eight character spaces (or $2 \mathrm{deg}$ of visual angle) and the mean duration of the fixation is around $200-250 \mathrm{msec}$. However, within a single subject reading a passage, there is a considerable amount of variability in both of these eye behavior characteristics such that the range of saccade extents is often between 1 and 20 character spaces and the mean fixation duration ranges from $100 \mathrm{msec}$ to over $500 \mathrm{msec}$ (Rayner \& McConkie, 1976). Rayner and McConkie (1976) found that there was no correlation between saccade length and fixation duration and concluded that these two components of eye behavior are not under the control of a single mechanism. Thus, an important goal for researchers interested in reading is to determine the control processes involved in each of these characteristics of eye movements in reading. Haber (1976) and Rayner and McConkie (1976) have described models of eye guidance for saccades in reading. The present paper deals with the nature of fixation durations during reading.

Two major positions have traditionally been taken with regard to the fixation periods during reading. The first position, which will be referred to as the cognitive lag hypothesis, suggests that the eye movements are so rapid and the durations of the fixations so short that the semantic processing of the text must necessarily lag behind the perceptual input of the stimulus (Kolers, 1976; Morton, 1964). The

Analysis of the data for the present paper was supported by Grant BNS76-05017 from the National Science Foundation and Grant MH25868 from the National Institute of Mental Health to the author. The author would like to express appreciation to Robert G. Crowder, Carla J. Posnansky, George W. McConkie, and two anonymous reviewers for their helpful comments on an earlier draft of the present paper. Requests for reprints should be addressed to Keith Rayner, Center for Development, Learning, and Instruction, or Department of Psychology, University of Rochester, Rochester, New York 14627. second position, which will be called the process monitoring hypothesis, suggests that the eye movements and fixation durations are affected by the cognitive processes occurring during the time period of the fixation (Rayner \& McConkie, 1976). Thus, more difficult words and passages should lead to longer fixation durations. It should be noted that these two positions represent extreme positions and intermediate positions could also be hypothesized.

While there is fairly widespread support for both positions, there is little conclusive evidence that either position is correct. It has been demonstrated that both difficult passages (Tinker, 1965) and embedded sentences (Klein \& Kurkowski, 1974) lead to more fixations and longer average fixation durations. However, both demonstrations rely on very global aspects of eye movements and do not deal with moment to moment changes as a function of difficulty. Blumenthal (1970) has pointed out that a number of early researchers, such as Dearborn and Dodge, attempted to relate fixation duration and location to specific aspects of language. Their attempts were unsuccessful and led to the conclusion that a reader is as likely to fixate on unimportant function words as he is to fixate on more substantive parts of the sentence. Their results may have been largely due to the lack of an adequate description of the language at the beginning of the 20th century and to measurement inaccuracies. Nevertheless, these results have traditionally been taken as evidence against a process monitoring hypothesis.

More recently, there have been some studies which could be taken as being supportive of the process monitoring hypothesis. Pynte (1974) had French subjects move their eyes from left to right fixating on a series of two-digit numbers which were at least 10-15 deg apart. The middle number was made up of the same digits, but varied in the number of syllables necessary to pronounce it. The numbers 82 (quatre-vingt-deux) and 28 (vingt-huit) were used. The subject's task was to report back the series of digits. 
Pynte found that the amount of time the eye fixated on a number was related to the number of syllables it contained. Rayner (1975a) had subjects read passages of text and changed visual and lexical characteristics of certain key words while the eye was in motion. He found differences in fixation duration on these key words as a function of the types of changes made. He also found that when a subject fixated on a nonword there was a significantly increased duration.

In addition to the studies by Pynte and by Rayner, there have recently been some studies relating fixation duration to certain grammatical considerations. Mehler, Bever, and Carey (1967) reported that readers tend to fixate the first half of the immediate constituent unit. Gibson and Levin (1975) and Wanat (1971) have criticized this study on the grounds that (1) there was a higher diversity of fixations than most studies have shown, and (2) forward fixations and regressions were not differentiated. The latter point is important because ambiguous sentences were used in the study and it would seem reasonable to expect large numbers of regressions to disambiguate the sentences. In addition to these limitations, it is also true that Mehler et al. (1967) discarded approximately half of their data. For example, they discarded sentences if there were a large number of fixation points on the photographic record for that sentence. As Wanat (1971) has pointed out, a case in which a reader had to fixate many points suggests factors in the sentence which made it difficult to process. Yet, this served as a basis for discarding data. Finally, with regard to the Mehler et al. study, it should be noted that a recent attempt to replicate the results failed (O'Regan, 1975).

Wanat (1971) photographed the eye movements of readers as they read sentences that differed in predictability. Wanat was following up on studies of the eye-voice span carried out by Levin and his colleagues (cf. Levin \& Kaplan, 1970). The eye-voice span has been found to be larger at the end of passive sentences (which are more predictable) than at the end of active sentences. It is also larger in more predictable left embedded sentences than in right embedded sentences, and in agent included passive sentences than in agent deleted passives. In general, Wanat found a reasonable match between the eye-voice span findings and the pattern of eye movements. Where the eye-voice span had been long, he found the eye movement data showed fewer fixations, briefer fixation durations, and fewer regressions. Wanat also reported that inspection time tends to be greatest in the area of the main verb of the sentence. Dividing the sentence frame into different areas, he found that the area of the sentence in which the sentence score for the left embedded sentence exceeded the right embedded sentence was in the area of the main verb of the left embedded sentence. Similarly, the area of the sentence in which the score for the right embedded sentences exceeded the left embedded sentences was in the area of the main verb.

Wanat's results imply that the verb is very important in processing the sentence, and are paralleled by studies that have reported that tampering with the main verb of the sentence interferes most with fluent processing (Gladney \& Krulee, 1967); that the main verb is the central element in sentence comprehension (Fodor, Garrett, \& Bever, 1968); and that the main verb is most important in determining the meaning of the sentence (Healy \& Miller, 1970, 1971). Recent theorizing by linguists (Chafe, 1970; Fillmore, 1968) also points out the importance of the verb in processing and comprehending a sentence. One problem with Wanat's (1971) results concerning the verb of the sentence is that his scoring technique did not allow for comparisons of the verb with other key grammatical elements in a sentence. Communale (1973) noted this and carried out a study in which subjects read active sentences while he recorded the eye movements. He inserted a prepositional phrase at the beginning of the sentence, after the subject and prior to the verb, after the verb and prior to the object, or at the end of the sentence. Sentences in which the prepositional phrase came at the beginning or end yielded longer mean fixation durations on the verb (by $20-40 \mathrm{msec}$ ) than on the subject or object. Sentences in which the prepositional phrase was embedded in the middle of the sentence yielded different patterns. However, sentences of this type are somewhat difficult to understand and this fact may have been the major reason for the differing results.

Subjects in the present experiment read active sentences much like those used by Communale (1973) and by Healy and Miller (1970). However, the sentences were presented in context rather than in isolation, as was the case in the prior studies. In some respects, the present study is similar to Communale's, in that comparisons were between key grammatical elements in the sentence in terms of visual attention. Methodologically, the present study made use of an on-line computer recording technique (cf. Rayner, 1975a; Reder, 1973) which provided more accurate recording of fixation location and duration than the photographic techniques used by Communale (1973) and Wanat (1971).

\section{METHOD}

\section{Subjects}

Ten undergraduate students at the Massachusetts Institute of Technology were paid to participate in the study. All had normal, uncorrected vision and reading speeds between 200-500 words/min. Each subject read a series of short passages and was instructed to read the passage for meaning. They were told that the purpose of the study was to determine what people look at when they read. The eye movement records were collected as part of a study which included display changes during reading (Rayner, 1975a). All of the data reported in the 
present paper are from conditions in which there were no display changes.

\begin{abstract}
Materials
A set of 225 sentences was prepared that took the following syntactic form: Sentence $=$ The + subject + verb + the + object + prepositional phrase. Each sentence was embedded in a short passage which was 35-40 words in length. The data reported here are based upon 45 passages read by each subject in which there were no display changes; each pair of subjects read a different subset of 45 passages. The mean length in character spaces for all words filling the grammatical category of subject, verb, and object was $6.2,6.0$, and 5.9, respectively. Mean word frequency (Kučera \& Francis, 1967) of words filling each grammatical category was 75,98 , and 79 for subject, verb, and object, respectively.
\end{abstract}

\section{Apparatus and Procedure}

On-line recording of eye movements was accomplished by interfacing a Biometrics Model SG Eye Movement Monitor with a PDP-6 computer. A biteboard and a headrest were used to prevent head movements. As the subject read the text, the computer kept a complete record of fixation location, fixation duration, saccade duration, and saccade length. Pilot work with the eye movement apparatus indicated that it was reasonably accurate and seldom indicated that a reader was fixated more than one or two character positions away from the character he reported he was fixating.

The text was displayed on a Digital Equipment Corporation Model 340 display scope with a P-7 phosphor, covered by dark blue theater gel. The scope had a character generator for both upper- and lowercase letters. Each line of text displayed was approximately 72 characters long, which occupied $18 \mathrm{deg}$ of visual angle.

When a subject arrived for the experiment, a biteboard was prepared for him. Then the eye tracking sensors, which were mounted on glasses frames and held securely by a headband, were placed on him and adjusted. Each subject read two or three short warm-up passages in order to become adjusted to the apparatus. Following the warm-up passages, the subjects read the text used in the study. They were told to read the passages as they would normally do to understand them, and that after they read a sequence of passages they would be tested by being shown a series of sentences from which they were to select the sentences which had appeared in their reading. Performance on the recognition tests was very high and subjects rarely falsely identified a new sentence or missed an old sentence.

\section{RESULTS}

A number of different measures of eye movement behavior relating visual attention to different grammatical categories were analyzed. These measures can be divided into four general categories: (1) number of fixations, (2) fixation durations, (3) total time, and (4) saccade lengths. For each of the dependent variables, an analysis of variance was performed on the data. Table 1 lists the significant effects as well as the means.

As seen in Table 1, data regarding eye movements on the prepositional phrases were not analyzed. This was because the prepositions used, as well as the objects of the prepositions, were considerably more variable in terms of length than the other elements of the sentences used. It is also important to note that the reader's fixation point sometimes fell on the space between two words. On these occasions, the fixation was considered to be on the word to the right of the fixation point for forward fixations and on the word to the left of the fixation point on a regression. This seemed to be a reasonable assumption, since there is evidence that for forward fixations readers process information mainly to the right of the fixation point (McConkie \& Rayner, 1976).

In a natural reading situation, the experimenter does not have nor desire control over where the reader chooses to fixate. Consequently, on some occasions important elements in the sentence will not be fixated directly. Furthermore, an examination of eye movement records indicates that there is a great deal of variability between readers as far as which words are skipped, which suggests that eye movement patterns may be to some extent idiosyncratic to a particular reader. Thus, means of eye movement behavior for each grammatical category were used as the dependent measures in the analyses of variance that were performed. Since each pair of subjects read a different sample of text, the Subjects by Treatment interaction was used as the appropriate error term (Clark, 1973) in the analyses.

Table 1

Means of Significant Effects

\begin{tabular}{|c|c|c|c|c|c|c|c|}
\hline & The & $\underline{S}$ & $\mathbf{V}$ & the & 0 & F Value* & $\begin{array}{c}\begin{array}{c}\text { Significance } \\
\text { Level }\end{array} \\
\end{array}$ \\
\hline $\begin{array}{l}\text { Number of Fixations** } \\
\text { Forward Fixations } \\
\text { Regressive Fixations }\end{array}$ & $\begin{array}{r}10.5 \\
2.7\end{array}$ & $\begin{array}{r}47.4 \\
8.1\end{array}$ & $\begin{array}{r}47.2 \\
8.1\end{array}$ & $\begin{array}{r}21.8 \\
3.6\end{array}$ & $\begin{array}{r}42.5 \\
7.5\end{array}$ & $\begin{array}{r}78.30 \\
9.05\end{array}$ & $\begin{array}{l}.001 \\
.001\end{array}$ \\
\hline $\begin{array}{l}\text { Fixation Durations (msec) } \\
\text { Forward Fixations } \\
\text { Regressive Fixations }\end{array}$ & $\begin{array}{l}167 \\
123\end{array}$ & $\begin{array}{l}204 \\
185\end{array}$ & $\begin{array}{l}231 \\
233\end{array}$ & $\begin{array}{l}208 \\
135\end{array}$ & $\begin{array}{l}214 \\
212\end{array}$ & $\begin{array}{r}14.43 \\
5.51\end{array}$ & $\begin{array}{l}.001 \\
.002\end{array}$ \\
\hline $\begin{array}{l}\text { Total Time (msec) } \\
\text { Per Character F } \\
\text { Total Time Per Character }\end{array}$ & $\begin{array}{l}15 \\
19\end{array}$ & $\begin{array}{l}35 \\
42\end{array}$ & $\begin{array}{l}41 \\
49\end{array}$ & $\begin{array}{l}36 \\
41\end{array}$ & $\begin{array}{l}36 \\
44\end{array}$ & $\begin{array}{l}19.18 \\
22.82\end{array}$ & $\begin{array}{l}.001 \\
.001\end{array}$ \\
\hline
\end{tabular}

*The degrees of freedom in all cases are 4/36.

**Mean number of fixations per subject (based on 45 sentences per subject). 


\section{Number of Fixations}

Forward fixations and regressions were analyzed separately. As seen in Table 1, grammatical elements in the sentences received differing numbers of fixations. A Newman-Keuls test indicated that the first "the" in the sentence received fewer fixations than the second "the" which, in turn, received fewer fixations than the object. The subject and the verb did not differ from each other, but did receive significantly more fixations than the object. At first glance, this finding would suggest that the object received less visual attention than the subject or verb. However, a closer examination of the data indicated that subjects sometimes fixated on the function word prior to the object and skipped the object. A separate analysis in which fixation on the word "the" but not on the object was counted as fixating the object yielded no significant differences between the subject, verb, and object. An analysis in which fixations on the first function word were counted as fixations on the subject was not carried out for two reasons. First, there were considerably fewer fixations on the first function word than the second (see Table 1); and, second, while subjects occasionally fixated on the second function word and skipped the object, instances where the first function word was fixated and the subject was skipped were quite rare. Thus, it appears that the original result can be explained by the notion that when the reader fixated on the second function word, on some occasions the object of the sentence was within a region of acuity such that the reader was able to process its meaning.

A Newman-Keuls test on the data on number of regressive eye movements indicated that there were fewer regressions to the function words than to the subject, verb, or object, which did not differ from each other. It is worth noting that some of the regressions were multiple regressions, in that the reader may have fixated on the subject position (for instance), advanced to the verb, regressed to the subject, moved forward again, only to regress a second time to the subject.

\section{Fixation Durations}

A Newman-Keuls test on the forward fixation duration data indicated that fixations on the first function word were significantly shorter than fixations on the second function word, the subject, and the object. The durations of fixations on these three categories were significantly shorter than the durations on the verb of the sentence $(p<.01)$. Durations of regressive movements yielded a similar pattern, but should be interpreted cautiously, since there was a considerable amount of missing data due to the infrequency of regressions by some subjects.

\section{Total Time}

Analyses of variance on the total time spent in forward fixations and the total time spent in regressive fixations yielded results identical to the fixation duration data. Two other analyses were carried out which took into account the fact that the function words were shorter than the content words. The first analysis, referred to as "per character $F$ " in Table 1, involved dividing the number of characters of the words in each grammatical category into the total time spent in forward fixations. The second analysis, referred to as "total time per character" in Table 1 , involved a similar procedure but included both forward fixation time and regressive fixation time. Newman-Keuls tests for both analyses indicated that the first function word received less total time per character than did the second function word, the subject, and the object. These categories, in turn, received less visual attention than did the verb.

\section{Saccade Lengths}

An analysis of variance on the length of saccades leaving the different grammatical categories yielded an $F$ that reached the $10 \%$ level of confidence. However, an examination of the means indicated considerable individual differences, and as a result added variability, among subjects for lengths of saccades leaving the function words. That is, some subjects did not fixate on the content word if they had fixated on the preceding function word, while other subjects occasionally fixated on both the function word and the content word. In addition, it is important to note that the function words were not fixated as frequently as the content words and, as a result, means for saccade lengths leaving those areas would not be as stable as the means for the content words. Another analysis which included only the grammatical categories of subject, verb, and object yielded a significant effect $[F(2,18)=8.96, p<.01]$, and saccades leaving the subject position were shorter than those leaving the verb or object (means $=6.9,8.2$, and 7.8 character spaces for subject, verb, and object, respectively). The major reason for this was probably the fact that the verb immediately followed the subject in the syntactic construction of the sentences used in this study. The verb and object, on the other hand, were followed by short function words or prepositions which often were not fixated.

\section{DISCUSSION}

The finding that the main verb in simple active sentences received longer fixation durations than other parts of the sentence replicates results obtained previously by Communale (1973) and Wanat (1971). The result is also consistent with a number of previous studies mentioned earlier in this paper which indicated the importance of the main verb in comprehending a sentence. Recent linguistic theory, particularly case grammar (Fillmore, 1968), also implicates the central role of the verb in sentence processing. According to case grammar, a case accounts for a distinct type of 
semantic relationship between the verb and its arguments. The verb also serves the function of specifying the action which the main nouns in the sentence enter into. Thus, the longer fixation durations on the verb may be accounted for by the notion that when the reader reaches the main verb in a simple active sentence, the relationship between the subject noun and the verb can be specified. Unless the reader is able to understand the relationship specified by the verb, the sentence is meaningless. This was demonstrated in a study by Gladney and Krulee (1967) in which the subject noun, verb, or object noun was replaced by an adverb or adjective. Readers had the most difficulty gleaning some meaning from sentences in which the verb had been replaced. While there is evidence that the verb is particularly important in the initial processing of a sentence, there is also evidence that the verb does not play as central a role in the memory representation of the sentence, since it is often more poorly recalled or recognized than the key nouns in the sentence (Reynolds \& Flagg, 1976; Zargar-Yazdi, 1973). Also, although the present study and others found longer fixations on the verb, Rayner (1975b) found no indication that a mutilation of the main verb could be detected any further from fixation in reading than a mutilation of the subject or object.

While the present study as well as the studies by Communale (1973) and Wanat (1971) found longer fixations on the main verb of the sentence, it is important to note that instructions to the readers and complexity of syntactic structure may influence fixation patterns in reading. Zargar-Yazdi (1973) had subjects read passages of text with sentences of varying types of syntactic structure. He found that nouns and verbs were fixated more frequently than other types of words. Verbs and nouns did not differ from other types of words in terms of the duration of fixations upon them. Zargar-Yazdi (1973) did point out, however, that the mean fixation duration for verbs generally was larger than for nouns, but the difference was not statistically significant due to the large within-groups variance. Zargar-Yazdi manipulated instructions to the subjects, sometimes telling them that they would have to recall nouns from the passage and sometimes verbs. Mean fixation durations on the verbs were significantly longer when subjects were told they should recall verbs (recall for the verbs was not better, however). As indicated above, fixation durations on the verbs were also longer in other instruction conditions, but not significantly so. With respect to the suggestion that complexity of syntactic structures may influence eye movement patterns, it has been demonstrated that certain types of syntactic structure result in more and longer fixations (Communale, 1973; Klein \& Kurkowski, 1974). Communale (1973) found that sentences in which the prepositional phrase was embedded either prior to or after the verb resulted in fixation patterns which were different from sentences in which the prepositional phrase occurred at the beginning or end of the sentence. Thus, while there is evidence that verbs in active sentences receive longer fixations, it may be that with more complex sentence structures the same pattern does not hold. Such a consideration leaves open the important possibility that eye movement data can provide important insights into the nature of processing sentential information.

With respect to the two hypotheses discussed in the introduction of the present paper, the results of the present experiment provided evidence that eye movements in reading are affected by cognitive processes. First, as discussed above, it was found that the main verb of the sentence received longer fixation durations than the subject noun and the object noun. In addition, function words beginning a sentence were not fixated as frequently as other words and when they were fixated the durations were significantly shorter. Function words occurring prior to the object of the sentence were fixated as frequently as the subject, verb, and object when the length of the word was taken into account. In addition, fixations on the second function word were as long as fixations on the subject and object nouns. As was pointed out earlier, readers sometimes fixated on the second function word and skipped the object. It may be that on such occasions the object of the sentence fell within an area of the perceptual span (Rayner, 1975a) such that readers could identify the object.

While the data discussed above provide support for the notion that fixation durations are affected by cognitive processes, other aspects of the present data set could be adduced to argue for this notion. First, fixation durations on infrequent words were compared with the preceding fixation duration and the two following fixations. Fixation durations on the infrequent word (frequency counts of less than six in the Kucera and Francis corpus) were about $60 \mathrm{msec}$ longer than the preceding fixation, $30 \mathrm{msec}$ longer than the following fixation $(n+1)$, and 50 msec longer than the next fixation $(n+2)$. Unfortunately, it was not possible to control for word length and word class considerations, but the general result that infrequent words received longer fixations is consistent with earlier observations (Dearborn, 1906; Kolers, 1976) and with the process monitoring hypothesis. Second, the initial fixation on a line was longer than subsequent fixations on the line (by $30-50 \mathrm{msec}$ on the average) and the final fixation was shorter than other fixations. This observation is also consistent with earlier observations (Abrams \& Zuber, 1972; Dearborn, 1906; Hawley, Stern, \& Chen, 1974) and could be used to argue for the process monitoring hypothesis. In essence, the argument is that differences between the duration of the first and the last fixation on a line could be attributed to parafoveal and peripheral processing (Rayner, 1975a). That is, with the first fixation on a line, the reader has not had the opportunity to do any 
type of preprocessing of that area as he has for later fixations on the line. On the other hand, with the last fixation on a line, there is no necessity of engaging in parafoveal preprocessing of information to the right of the fixation point. All the reader has to do is program a return sweep of the eye to the beginning of the line. Since the beginning of the next line is too far away (in terms of acuity characteristics) to obtain any useful information, the task on the last fixation on a line is to process the foveal information and program the return sweep (Abrams \& Zuber, 1972). While such an argument is consistent with the process monitoring hypothesis, it should be noted that an interpretation of fixation durations as a function of location on the line is somewhat ambiguous. For example, the longer fixation at the beginning of the line could be due to the lack of prior parafoveal processing, or it could be due to purely visual factors such as the possibility that monocular accommodation is detuned during the return sweep and, consequently, focus is imperfect at the outset of the initial fixation, slowing information processing.

In summary, the results of the present experiment, as well as the results of a number of studies reviewed earlier in the present study, converge on the fact that fixation durations in reading are affected by cognitive processes. Thus, it would seem that eye movement data may provide answers to many interesting questions about reading and sentence processing.

\section{REFERENCES}

Abrams, S. G., \& Zuber, B. L. Some temporal characteristics of information processing during reading. Reading Research Quarterly, 1972, 12, 41-51.

Blumenthal, A. Language and psychology. New York: Wiley, 1970.

ChAFE, W. Meaning and the structure of language. Chicago: University of Chicago Press, 1970.

Clark, H. H. The language-as-fixed-effect fallacy: A critique of language statistics in psychological research. Journal of Verbal Learning and Verbal Behavior, 1973, 12, 335-359.

Communale, A. S. Visual selectivity in reading: The relationship between eye movements and linguistic structure. Unpublished doctoral dissertation, University of Massachusetts, 1973.

DEARBORN, W. F. The psychology of reading. Archives of Philosophy, Psychology, and Scientific Methods, 1906.

Fillmore, C. J. The case for case. In E. Bach \& T. Harms (Eds.), Universals in linguistic theory. New York: Holt, 1968.

Fodor, J. A., Garrett, M., \& Bever, T. G. Some syntactic determinants of sentential complexity, II: Verb structure. Perception \& Psychophysics, 1\%68, 3, 453-461.

Gibson, E. J., \& LEviN, H. The psychology of reading. Cambridge, Mass: MIT Press, 1975.

Gladney, T. A., \& Krulee, G. K. The influence of syntactic errors on sentence recognition. Journal of Verbal Learning and Verbal Behavior, 1967, 6, 692-698.

HABER; $R$. N. Control of eye movements during reading. In R. A. Monty \& J. W. Senders (Eds.), Eye movements and psychological processes. Hillsdale, N.J: Lawrence Erlbaum, 1976.

Hawley, T., Stern, J. A., \& Chen, S. C. Computer analysis of eye movements during reading. Reading World, 1974, 13, 307-317.

Healy, A. F., \& Miller, G. A. The verb as the main determinant of sentence meaning. Psychonomic Science, $1970,20,372$.

Healy, A. F., \& Miller, G. A. The relative contribution of nouns and verbs to sentence acceptability and comprehensibility. Psychonomic Science, 1971, 24, 94-95.

KLEIN, G. A., \& KuRKowski, F. Effect of task demands on relationships between eye movements and sentence complexity. Perceptual and Motor Skills, 1974, 39. 463-466.

Kolers, P. Buswell's discoveries. In R. A. Monty \& J. W. Senders (Eds.), Eye movements and psychological processes. Hillsdale, N.J: Lawrence Erlbaum, 1976.

KuĆERA, H., \& Francis, W. N. Computational analysis of present-day American English. Providence, R.I: Brown University, 1967.

Levin, H., \& KaPlan, E. L. Grammatical structure and reading. In $H$. Levin \& $J$. P. Williams (Eds.), Basic studies on reading. New York: Basic Books, 1970.

McConkie, G. W., \& RAYNeR, K. Asymmetry in the perceptual span in reading. Bulletin of the Psychonomic Society, 1976, 8, 365-368.

Mehler, J., Bever, T. G., \& Carey, P. What we look at when we read. Perception \& Psychophysics, 1967, 2 213-218.

Morton, J. The effects of context upon speed of reading, eye movements, and eye-voice span. Quarterly Journal of Experimental Psychology, 1964, 16, 340-354.

O'REGAN, J. K. Structural and contextual constraints on eye movements in reading. Unpublished doctoral dissertation, University of Cambridge, 1975.

Pynte, J. Readiness for pronunciation during the reading process. Perception \& Psychophysics, 1974, 16, 110-112.

RAYNER, $K$. The perceptual span and peripheral cues in reading. Cognitive Psychology, 1975, 7, 65-81. (a)

RAyner, K. Parafoveal identification during a fixation in reading. Acta Psychologica, 1975, 39, 271-282. (b)

RAYNER, K., \& MCCONKuE, G. W. What guides a reader's eye movements? Vision Research, 1976, 16, 829-837.

Reder, S. M. On-line monitoring of eye position signals in contingent and noncontingent paradigms. Behavior Research Methods \& Instrumentation, 1973, 5, 218-228.

Reynolos, A. G., \& Fl.AGG, P. W. Recognition memory for elements of sentences. Memory \& Cognition, 1976, 4, 422-432.

TINKER, M. A. Bases for effective reading. Minneapolis: University of Minnesota Press, 1965.

WANAT, S. Linguistic structure and visual attention in reading. Newark, Del: International Reading Association, 1971.

ZARGAR-YAZDI, A. An investigation of reading: Eye movements and word recall. Unpublished doctoral dissertation, Stanford University, 1973.

(Received for publication March 14, 1977; revision accepted A pril 29, 1977.) 